\title{
Revue de I'IFHA
}

Revue de l'Institut français d'histoire en Allemagne

Syndicats, patronat et conventions collectives en Allemagne de 1992 à 2008. L'évolution du système conventionnel à travers les publications des instituts de recherche WSI (Wirtschafts- und Sozialwissenschaftliches Institut) et IW (Institut der deutschen Wirtschaft)

\section{Christine Aquatias}

\section{OpenEdition \\ Journals}

Édition électronique

URL : http://journals.openedition.org/ifha/8078

DOI : 10.4000/ifha.8078

ISSN : 2198-8943

Éditeur

IFRA - Institut franco-allemand (sciences historiques et sociales)

Édition imprimée

Date de publication : 31 décembre 2014

ISSN : 2190-0078

\section{Référence électronique}

Christine Aquatias, « Syndicats, patronat et conventions collectives en Allemagne de 1992 à 2008. L'évolution du système conventionnel à travers les publications des instituts de recherche WSI ( Wirtschafts- und Sozialwissenschaftliches Institut) et IW (Institut der deutschen Wirtschaft) ", Revue de I'IFHA [En ligne], 6 | 2014, mis en ligne le 31 décembre 2014, consulté le 03 mai 2019. URL : http:// journals.openedition.org/ifha/8078; DOI : 10.4000/ifha.8078

Ce document a été généré automatiquement le 3 mai 2019.

(CIFHA 
Syndicats, patronat et conventions collectives en Allemagne de 1992 à 2008. L'évolution du système conventionnel à travers les publications des instituts de recherche WSI (Wirtschafts- und Sozialwissenschaftliches Institut) et
IW (Institut der deutschen
Wirtschaft)

Christine Aquatias

1 Le fonctionnement des relations sociales est traditionnellement considéré comme l'une des caractéristiques de l'économie allemande. Au lendemain de la Seconde Guerre mondiale, à l'Ouest, les Alliés étaient d'accord sur le principe de l'abandon du système de réglementation national-socialiste du travail et souhaitaient le retour à une négociation des conventions collectives par branche d'activité, entre syndicats et associations patronales, semblable à celle en vigueur sous la République de Weimar. Pendant des décennies, le système conventionnel mis en place en 1949, qui accordait aux partenaires sociaux une réelle autonomie décisionnelle face à l'État, fut perçu, y compris à l'étranger, comme un modèle de fonctionnalité et de régularité, comme l'archétype d'une gestion policée d'intérêts divergents. Or, au lendemain de l'unification des deux États allemands, les transformations du système conventionnel, dont les prémisses remontent aux années 1980, s'accélérèrent. À partir de 1992, la nature, le type, le nombre des conventions collectives évoluèrent de manière frappante, ainsi que l'attitude des parties contractantes elles-mêmes envers le système. Il semblait que d'un côté, le patronat fût de plus en plus 
mécontent du dispositif. De l'autre côté, les syndicats dénonçaient les salaires de misère dus à l'absence désormais fréquente de conventions collectives dans certains secteurs d'activité. La question de l'efficience du dispositif investit la scène publique au point que certains partis franchirent le pas et réclamèrent l'introduction d'un salaire minimum fixé par la loi, valable pour toutes catégories professionnelles et dans toute l'Allemagne. Ce fut du reste l'un des thèmes récurrents sur lesquels débattirent les partis en campagne lors des élections législatives de 2005, 2009 et 2013. On sait que la CDU/CSU (Christlich Demokratische Union / Christlich-Soziale Union) et le SPD (Sozialdemokratische Partei Deutschlands) convinrent à l'automne 2013, durant la négociation du contrat de coalition en vue de la formation d'un gouvernement, d'introduire en Allemagne un salaire minimum.

2 Comment en était-on arrivé là? Notre projet était d'étudier l'évolution du système conventionnel et tous aspects en lien avec elle, en amont ou en aval : les facteurs qui la causèrent ou l'amplifièrent et les implications qu'elle eut, sur les plans national et international. Les protagonistes étant concernés au premier chef, nous avons fait reposer l'étude sur les publications de deux instituts de recherche, l'un réputé proche du patronat, Institut der deutschen Wirtschaft (IW), l'autre proche des syndicats, Wirtschaftsund Sozialwissenschaftliches Institut (WSI) - deux instituts de recherche bien connus en Allemagne. L'exigence scientifique que revendique un institut de recherche permettait de supposer que les analyses publiées seraient argumentées, prendraient en considération des éléments contradictoires, se référeraient à des études reconnues. L'idée directrice de notre travail était donc, tout en tenant compte de l'état de la recherche, de confronter les positions et résultats des deux instituts, afin d'accéder à une meilleure compréhension, nourrie d'approches divergentes mais parfois complémentaires, de phénomènes complexes. Les publications retenues furent Trends, Gewerkschaftsreport, Unternehmen und Gesellschaft pour l'IW, WSI-Mitteilungen pour le WSI. L'analyse a porté sur la période 1992 juillet 2008 (soit juste avant le déclenchement en Europe de la crise financière).

3 La première partie est consacrée à des rappels historiques et juridiques ainsi qu'à un premier bilan tant qualitatif que quantitatif des transformations du dispositif conventionnel entre 1992 et 2008 . Elle fournit les éléments nécessaires à l'intelligence du fonctionnement du système et une appréhension de l'envergure et de la nature de ses transformations. La deuxième partie propose une exposition chronologique des phénomènes, segmentée en cinq périodes adossées au contexte politique et socioéconomique. La troisième partie est consacrée aux acteurs de la négociation conventionnelle et aux bouleversements qui les affectent durant la période considérée. Enfin, la quatrième partie s'attache à l'influence du nouvel ordre économique mondial (dont européen) sur le système conventionnel allemand.

La mise en perspective des publications s'est avérée fructueuse et enrichissante. Maintes fois, elle a permis de montrer que de vrais débats s'engagent entre les instituts par périodiques interposés - sur la définition de ce qu'est la «compétitivité" par exemple. Elle a également mis en lumière l'importance grandissante de la communication et des techniques de communication durant cette période. 


\section{AUTEUR}

\section{CHRISTINE AQUATIAS}

Université de Metz 